\title{
The systemic paradigm of the modernization of the Russian energy for the purpose of sustainable development
}

\author{
Elena Krasilnikova*, and Alla Nikonova \\ Central Economics and Mathematics Institute of the Russian Academy of Sciences, Nahimovsky Pr., \\ 47, 117418 Moscow, Russia
}

\begin{abstract}
Keeping in mind the significant dependence of the Russian economy on oil and gas revenues coupled with the low energy efficiency and technology backwardness, the country faces noticeable threats to its technological and economic sustainable development. Findings of a system analysis of the Russian energy sector indicate the need for organizational and technological changes. It is found that easily available opportunities to get raw material rent, along with respective rules of the game, reduce economic agents' interest to innovations. External risks, such as sanctions, volatile energy markets, are not the root cause of the crisis in Russia, but these factors do destabilize the situation and make modernization more difficult. In this context, strategies and mechanisms that meet internal and external challenges are required. The novelty of the approach is that the improved systemic economic paradigm of innovation strategy formulation and support mechanisms implies moving the development drivers from the category of external impacts on the country's energy sector to the category of internal imperatives of its technological development through creation and stimulation of innovation and industrial ecosystems where the energy sector will serve as an infrastructure framework that consolidates all sectors of the economy.
\end{abstract}

\section{Introduction: the Modernization Prerequisites}

Modernization of the energy sector is investigated as bringing it in line with the socioeconomic, organizational, technological and environmental requirements of the modern world. In Russia, the need for modernization is becoming more and more acute, first of all, due to the low productivity, structural imbalance, obsolete equipment and outdated technologies in the fuel and energy complex. The energy sector is one of the backbones of the Russian economy. However, a number of internal industry-specific problems (worn-out grids and equipment, low generation efficiency, depletion of relatively easily accessible deposits, rising costs, etc.) cause low performance and poor competitiveness of the country's fuel and energy complex, undermine sustainability of the energy system and the national economy, and turn the country's possession of rich hydrocarbon resources from an advantage to a disadvantage. Because of its technological backwardness, Russian fuel and

${ }^{*}$ Corresponding author: krasilnikova_lena@list.ru 
energy complex is unable to efficiently perform its systemic functions such as provision of diversity, physical availability and price affordability, security, alternative choice of power supply sources. One third of Russian households do not have access to centralized gas supply; 42\% - hot water supply, 30\%are not provided with central heating, 19\% have problems with electric power supply [1, p. 179].

Secondly, the need for modernization is caused by the pressure of external conditions and factors, fundamental changes in the global power industry due to the spread of ICT, growing energy efficiency, adoption of energy saving and energy independence strategies, and transition to a clean, 'green' economy (replacement of fossil fuels with renewable energy sources (RES) and the use of new mineral production and power generation technologies). So there is a clear need to meet the global innovation trends. In addition, fluctuations in the global energy markets, increased competition among exporters, and deteriorating economic relations with the Western countries make it necessary for Russia to look for better ways to realize the country's energy potential in order to ensure sustainability and development of the energy sector and the national economy as a whole.

Almost tasks that make up the sustainable economic development goals can be attributed to the energy sector; these tasks include four groups of benchmarks aimed at its modernization: 1) efficient technologies; 2) social well-being; 3) ecology and environmental protection; 4) innovations, scientific development, technological advance.

As far as environmental pollution is concerned, carbon dioxide emissions in Russia do not yet exceed the European level but due to the features of Russia's economic structure there are many other types of emissions and pollutants in the country. In 2019, air pollution emissions in Russia amounted to 22.7 million tons (the shares of the transport and the industry being $1 / 4$ and $3 / 4$ respectively) of which $21 \%$ fall on metallurgy. The per-capita quantity of harmful emissions in Russia is about $155 \mathrm{~kg}$ per year (this number ranges from $23 \mathrm{~kg}$ to $1.6 \mathrm{t}$ depending on the region). The regions with the highest pollutant emissions are the Krasnoyarsk Krai (metallurgical industry), the Kemerovo Oblast (coal mining), the Khanty-Mansi Autonomous Okrug (oil and gas), the Sverdlovsk Oblast, the Yamal-Nenets Autonomous Okrug, the Irkutsk Oblast, the Republic of Bashkiria, the Chelyabinsk Oblast.

As provided by the Ecology national project, the plan is that by 2024 the country will not have any cities or towns with 'high' and 'very high' emission levels. The draft strategy of Russia's long-term development with low greenhouse gas emissions through 2050 outlines the transition to energy-saving technologies and reduced emissions after 2030.

\section{Methods: System Approach}

If the approach applied to studying the problems of the technical, technological, organizational and economic transformations and their implementation is intended to be system then it will require making strategic decisions and establishing regulatory mechanisms based on the system theory of economy. This theory includes several provisions that give an idea of the whole picture based on a system-thinking of the economy and the energy sector as systems, that is, relatively integral parts of the world that are closely related to each other and the environment. In their being, the components of the system exchange resources in different forms. From the standpoint of the systemic paradigm of economy, an economic or energy system consists of the four main components (sectors) distinguished on the basis of resources (capabilities) that they possess and that differ in their spatial and temporal characteristics [2]. This allows looking at the process of exchange (i.e., a form of interaction between agents) as a key element in the mechanism that ensures functioning of the entire system at the micro-level (the company), meso-level (the energy sector), macro-level (the national economy) or mega-level (the global system). According to the system paradigm, the balance of the system depends on how harmonious 
the process of exchange is. In this connection, it can be postulated that sustainability of the system depends on coordinated operation of the exchange mechanism and the equivalence of exchange in terms of how well each of the system elements performs its functions, and how fully the components complement each other. Based on this view, a conclusion can be drawn about the reasons why modernization of the Russian energy sector is not fast enough, and necessary regulatory and incentive mechanisms can be built.

To substantiate technological, organizational and economic decisions - modernization areas, priorities, and support tools - the development potential needs to be assessed. Such assessments can be made through a system analysis of the energy system and related sectors of the economy in the context of country characteristics and global structural and techno-scientific trends. Industry specifics and modernization challenges cause the analysis to be focused on the essential factors of successful modernization including opportunities and barriers. Among them, a significant role is played by institutional environment, quality of governance, as well as motivations and interests of economic agents.

\section{Analysis: Key Factors and Some Results}

Signs of innovation activity in the Russian energy sector show increasing differences between companies in the types of innovations implemented and the structure of innovation expenditures depending on the type of business, geography, and legal affiliation. The assessments made characterize two opposite trends. On the one hand, there is a serious demand from the energy sector for advanced world-class energy technologies for production and processing of fossil fuels and power generation that are not available in Russia. On the other hand, energy companies do not demonstrate any serious interest in large-scale investments in science, at least, judging by the amount of their own expenses for these purposes.

The diversity in behaviors of economic agents that implement innovations is a consequence of objective external and internal conditions: trends in development of the economy and society, specifics of the product and type of business, ownership structure, and economic policy of the government. This results in increased differentiation of economic agents, primarily by the level of their technology basis, productivity, profitability, and other indicators.

\subsection{Modernization Factors}

Preferences and interests of economic agents are extremely important for modernization measures. The degree of interest of corporations, owners, top managers, and other stakeholders in technology innovations is an essential factor. However, this tendency is not yet observed in the Russian energy sector.

Regulation of institutions, taxation, and other measures affect the pace and quality of innovations. The methods of influence comprise financial and non-financial levers including science and technology policy, foreign economic activity regulation, etc. Intensity of technology innovations and, as a result, the level of energy efficiency significantly depend on the quality of direct and indirect methods of influence applied by the regulator.

The econometric analysis results have shown that internal risks reduce the company's sustainable development and slow down its movement along the curve of its life cycle. It has been revealed that the company's belonging to the energy sector increases the probability for the company to be at the rapid growth stage. 


\subsection{Innovation Actors Behavior Patterns}

The demand for advanced energy technologies in the domestic market from the real sector companies is manifested in the growth of technology trade deals in the form of patents and license agreements. The share of the energy and electrical engineering industries in the technology market tends to grow and reached $15 \%$ in $2018,16.7 \%$ in petrochemical industries.

The social demand for modern energy technologies, including 'smart' technologies (e.g., smart grids), is evidenced by the preference structure of the population: $50 \%$ of respondents would like to have solar panels on their house roof, $49 \%$ would like to have an electric car, $45 \%$ would like to have a smart home [3, p. 26].

At the same time, innovation activity in the fuel and energy sector is low; moreover, since 2012 it has been declining, and even faster than in the economy as a whole. In other words, the propensity to innovation did not arise even at high oil prices: no 'groundwork' in the high technology area was made in the period of 2012-2014. In 2011-2016, the share of companies that implemented all types of innovations in the fossil fuel extraction sector decreased by one and a half times: from $11.3 \%$ to $6 \%$, including technological innovations - down from $9 \%$ to $5.5 \%$ and organizational innovations - down from $5.8 \%$ to $1.5 \%$. In the oil refining industry, the share of innovative companies is much higher than in oil production; however, innovative activity there is also decreasing (faster than in production). The number of companies that implement innovations in the heat and electrical power industry is $5-6 \%$ with a downward trend.

Environmental innovations were implemented mainly to ensure compliance with the current technical regulations, rules and standards, and to reduce costs. But they have little effect on the energy efficiency and $\mathrm{CO}_{2}$ emission. In Russia, only $5.8 \%$ of all companies that implemented environmental innovations managed to reduce power consumption or energy losses in power consumers, while in the EU this number ranges from $6.4 \%$ (Bulgaria) to $39 \%$ (Finland). In Russia, only about $6.7 \%$ of companies, who implemented ecology innovative have reduced energy consumption and carbon dioxide emissions while in the EU countries this number ranges from 6.4\% (Bulgaria) to 39\% (Finland) [4, p. 329330]. In Russia as a whole, the effect of innovations on energy efficiency (energy saving) is manifested in different ways: less a half of industrial companies experience a strong and medium effect (15\% and 29\% respectively) [4, p.245].

An increase in $R \& D$ has a non-parametric influence $\mathrm{CO}_{2}$ emission in G-7 countries: since 1955-1990 encourages and now trend is to decrease [5]. In Germany high tech strategy refers to defense environmental degradation.

The reluctance of companies to invest in science and technology is clearly expressed in the structure of expenditures [1, p.525]. Energy corporations, with the only exception of Rosatom and partly RusHydro, spend on R\&D projects much less than the three percent of the revenue recommended by the governmental programs. Many government-owned corporations have R\&D divisions in the absence of technological innovations: share of such corporations in the coal mining was about $100 \%$, fossil fuel production sector was $22,2 \%$, and in coke and petroleum products $-52.5 \%$, in the power generation, gas and water supply sector this share was about $85,7 \%$ [6, p.90-92]. For such corporations, it is easier and more profitable not to take risks with innovations than to buy separate technologies, even not the most advanced ones, and use machinery and equipment beyond the limits of wear and tear.

We have empirically estimated several effects to Russian data: an increase in GDP per capita, technical cooperation grants, investment in energy with private participation, $R \& D$ encourages production from renewable sources and renewable output.

Depreciation of fixed assets in the energy sector is higher than in many other industries of Russia: in the fossil fuel production industry it was $45.6 \%$, in mining $-55.6 \%$. Over $1 / 3$ of machinery and equipment is fully depreciated in mining, in electricity, gas, steam and air 
conditioning supply - 17.9\% [1, pp. 327, 332]. Operation of obsolete and worn out fixed assets and infrastructure leads to accidents and a decrease in the system's potential with respect to several components of its sustainability (as it happened in Norilsk on May 29, 2020 when 6,000 tons of diesel fuel spilled on the ground, 15,000 tons spilled into the river and from there - into the Kara sea; damage caused by this accident amounted to 100 billion rubles, and it will take 5-10 years to restore the environment). Such events reduce sustainability at all levels of the economy: at the micro level, the company's market value ran down and provisions for losses grew to one-fourth of EBITDA; and at the meso-level, people and the environment of a large region suffered. The growing Environmental, Social end Governance (ESG) risks also caused a reduction in the company's Fitch rating. Gazprom is in the top 10 of the MSCI emerging markets ESG Leaders Index. The weight of the environmental factor is often underestimated since the focus is on the governance factor which takes into account corporate governance and corporate behavior. The governance quality is assessed depending on harmonization of stakeholders' interests and relief of the principal-agent antagonism. The fact is that principal-agent conflicts and poor corporate governance make the company move along its life cycle curve from stability to stagnation.

Another aspect of the ESG concept is related to social factors, in particular, human capital. Human capital growth promotes smart consumption, transition from dirty to clean energy consumption, and reduces overall consumption by stimulating innovations for a panel sample of high-income OECD countries in the period of 1965-2014 [7]. Also improvement in human capital decreases energy consumption and conservation as example in India [8]. Based on econometric models to Russian data we have found that knowledge impact and a decrease inequality improved renewable output and renewable production.

Sanctions have had a negative impact on sustainability as they have restricted access to advanced technologies and financial sources of modernization. The share of innovation companies acquiring new technologies abroad decreased in the fossil fuel production sector from $19 \%$ to $6.3 \%$ (2014-2015), and in the petroleum products and coke production sector - from $54.5 \%$ to $46.2 \%$ (2014-2018) [6, p. 181-182; 9, p. 144-145].

Government documents do not provide for radical measures for the transition to new energy technologies. There are no «response measures», and internal regulation of emissions is clearly not enough: to achieve this goal, systemic strategic decisions in the sphere of science and technology are required.

\section{Discussion}

The governmental programs to modernize the fuel and energy sector, as well as the measures to improve energy efficiency have been failing to reach their goal so far. The transformation of the global energy system, the intensifying competition, and the transition to low-carbon technologies have also not become key drivers of modernization. On the one hand, this behavior of innovation actors can be explained by the existing rules of the game, regulatory conditions, and economic factors. These rules need to be changed in accordance with the system role of the fuel and energy sector in the national economy, in line with the goals and objectives of the socio-economic system stability.

In our opinion, formation of industrial and innovation ecosystems where the energy sector plays the role of a backbone that connects all other sectors by means of fuel and energy flows is a science-based solution which can best contribute to the technological renovation of the Russian fuel and energy sector. Creation and development of such ecosystems is a modern global trend [10]. The ecosystem is defined by the alignment structure of the multilateral set of partners that need to interact in order for a focal value proposition to materialize [11].And the backbone of ecosystems refers to no generic complementarities, and the creation of sets of roles that face similar rules [12]. 
Integration of innovation actors in a common institutional and cultural environment helps harmonize interests and interactions of commodity production, manufacturing, research, financial, and logistics companies. The benefits in this case will include better 'negotiability', lower transaction costs, easier and faster commercialization of R\&D results as well as deployment and spread of advanced technologies. Such systems are balanced and sustainable to external impacts since they generate internal development incentives based on close links in the exchange of resources and equivalent distribution of resource flows between the fuel and energy sub-sectors and the ecosystem environments including the natural environment, social environment, scientific and technological environment (Fig.1). To determine the metric of «fair» resource exchange between sectors of the socio-economic system, special assessment methods are required in the areas of subsurface resources management, environmental damage, human, social, and intelligent potential.

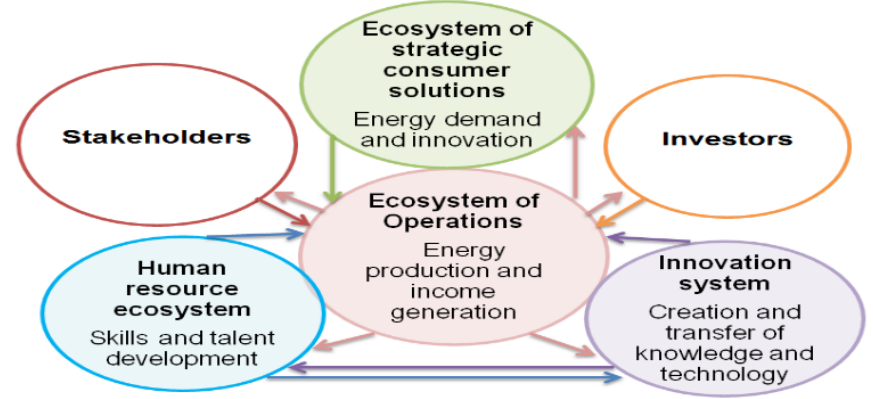

Fig. 1. Modernizing FEC in the framework of Schematic Ecosystem Model

With respect to Russian specifics, introduction of industrial and innovation ecosystems seems to be extremely promising but difficult to implement. A transitional measure in this situation would be to create innovative industrial clusters, for example, in oil refining centers like Sakhalin where LNG production is developed. Clusters can be considered as platforms for modernization of their participants and related companies involved both in energy and other economic activities $[13,14]$.

The systemic paradigm assumes achieving sustainability of the system based on balanced sectors and harmonization of interests of the stakeholders including national security interests and local competitiveness interests of energy companies. For this purpose, the energy strategies should be integrated into the system of macro-planning and scientific and technological development of Russia (Fig. 2).

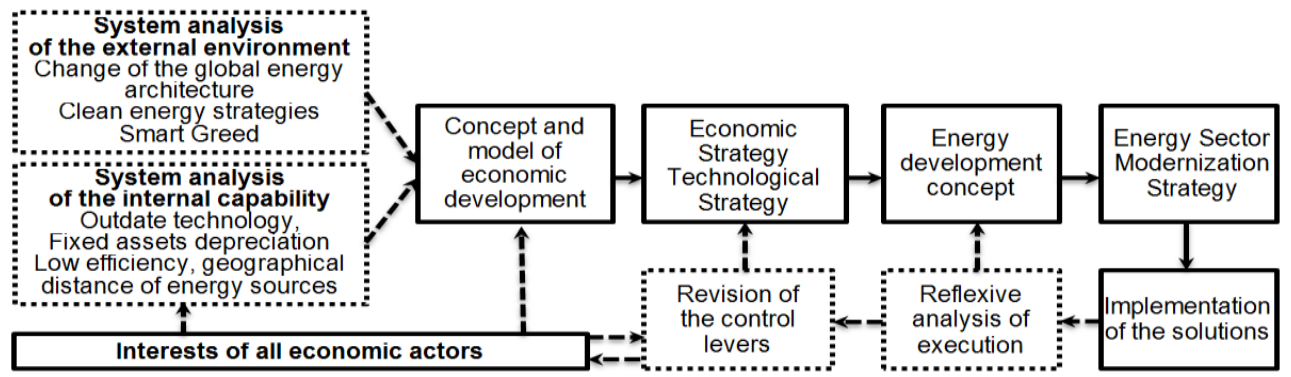

Note: The dotted line indicates blocks and links that are absent in Russian practice

Fig.2. System Paradigm of Strategic Planning for Modernization of the Fuel and Energy Sector 


\section{Conclusions}

Sustainability of the energy system is closely related to sustainability of the economy. From the of macro-system stability standpoint this means availability of cheap and safe energy, without damage to the natural environment. Sustainability of energy entities is based, first of all, on profitability of their business which is one of their key goals. In this context, it seems possible to coordinate macroeconomic and local interests on the basis of ecosystem models. In such models, the external regulation, organization and motivation loop can be configured using direct communication and feedback links to internal interaction mode that are implemented by the ecosystem actors through mutually beneficial exchange of resources. It will make economic agents interested in renovation of their technologies since they will be required to meet the needs of their ecosystem contractors and will focus on achieving their goals by means of technological development and care for the ecology environment. So a multiplicative effect from modernization can be obtained in the interests of all economic agents: 1) growth of budget revenues; 2) higher demand for innovations; 3 ) higher life quality; 4) new pattern (non-commodity) of the national economy growth.

The prospects for further research include methods and ways to build the industrial and innovation ecosystems. Another research area covers scientific approaches to assessing the social cost of energy as well as feasibility and effectiveness of introducing new technologies in the context of such factors as possible health damage, life quality deterioration and environmental pollution. At present, these factors are not taken into account very much when assessing new technology investment projects but such one-sided assessment of investments from the market stand point only distorts the structural investment policy and modernization strategies.

\section{Acknowledgements}

The article has been prepared as a part of the public task of the Central Economics and Mathematics Institute of the Russian Academy of Sciences on the topic No0328-2019-0005 and No 0162-2018-0004.

\section{References}

1. Russian Statistical Yearbook 2019: Stat .book (2019)

2. G.B. Kleiner, Economics Issues, 6 (2013)

3. V. Vlasova, L. Gokhberg et al., Russian Science and Technology in Figures (2018)

4. Industrial production in Russia 2019: Stat. coll. (2019).

5. Ch. S. Awaworyi, J. Inekwe, R. Smyth, X. Zhang, Energy Economics, 80 (2019)

6. L. Gokhberg, K. Ditkovsky, E. Evnevich, et all, Indicators of Innovation in the Russian Federation: 2020 (2020)

7. B. Akram, P. Jangam, B. Rath, B., Int. J. of Energy Sector Management, 13 (2019)

8. Y. Yao, K. Ivanovski, J. Inekwe, R. Smyth, Energy Economics, 84 (2019)

9. N. Gorodnikova, L. Gokhberg, K. Ditkovskiyet all, Indicators of innovation in the Russian Federation: 2017 (2017)

10. M.H. Best, Technovation, 39 (1) (2014)

11. R. Adner, J. of Management, 43 (1) (2017)

12. M. G. Jacobides, C. Cennamo, A. Gawer, Strat. Management J., 39 (8) (2018) 
13. H-J. Appelrath, H. Kagermann, Chr. Mayer (ed.) Future Energy Grid. Migration to the Internet of Energy (2012)

14. C-H. Lin, C.M. Tung, C-T. Huan, Technovation, 26 (2006) 